\title{
Lipoprotein (a)
}

\author{
Heterogeneity and Biological Relevance
}

Angelo M. Scanu*t and Gunther M. Fless*

Departments of ${ }^{*}$ Medicine, and ${ }^{\ddagger}$ Biochemistry and Molecular Biology, and

Lipoprotein Study Unit, University of Chicago, Chicago, Illinois 60637

Lipoprotein (a), or Lp(a), ${ }^{1}$ discovered by Kåre Berg (1) more than 25 years ago, remains today a fascinating subject of research both because of its presumed association with atherosclerotic cardiovascular disease (ASCVD) (2-14) and the many challenges it is offering to geneticists, structural biologists, physiologists, epidemiologists, cardiologists, and clinicians in general. Among these challenges is the elucidation of the remarkable heterogeneity exhibited by this lipoprotein particle, which is a key for understanding its biology. We will examine the various aspects of this heterogeneity and attempt to provide a global view on past and current knowledge on $\mathrm{Lp}(\mathrm{a})$ and identify those controversial areas where intensified research efforts are likely to provide important new advances.

\section{Physicochemical basis of heterogeneity}

The heterogeneity of $\mathrm{Lp}(\mathrm{a})$ went largely unrecognized until Harvie and Schultz (15) reported that their preparations of $\mathrm{Lp}(\mathrm{a})$ had a rather broad sedimentation coefficient distribution, and that $25 \%$ of them exhibited a bimodal Schlieren peak. The first systematic study on $\mathrm{Lp}(\mathrm{a})$ heterogeneity was carried out in 1984 by Fless et al. (16), who not only confirmed the findings of Harvey and Schultz but by studying individual rather than pooled human blood samples also found that $L p(a)$ exhibits both inter- and intra-individual density heterogeneity, and that this heterogeneity is accounted for by differences in protein and lipid composition. In the same study, they also observed that apolipoprotein(a) [apo(a)], the specific marker of $\mathrm{Lp}(\mathrm{a})$, exhibits size heterogeneity owing to species that have electrophoretic mobility either less than, equal to, or greater than that of apo $B_{100}$, the protein moiety of low density lipoprotein (LDL). In those studies it was also shown that apo(a) mass contributed to $\mathrm{Lp}(\mathrm{a})$ density in that the larger apo(a) was the main component of the denser particles and the smaller apo(a) was preferentially associated to $\mathrm{Lp}(\mathrm{a})$ particles of a low buoyant density. The importance of these studies did not be-

Address reprint requests to Dr. Scanu, Department of Medicine, University of Chicago, Box 231, 5841 South Maryland Avenue, Chicago, IL 60637.

Received for publication 19 January 1990 and in revised form 26 February 1990.

1. Abbreviations used in this paper: ASCVD, atherosclerotic cardiovascular disease; CE, cholesteryl ester; HMG, 3-hydroxy-3-methylglutaryl; K, kringle (for definition, see Fig. 1); Lp(a), lipoprotein (a); TG, triglyceride.

J. Clin. Invest.

(C) The American Society for Clinical Investigation, Inc.

0021-9738/90/06/1709/07 \$2.00

Volume 85, June 1990, 1709-1715 come immediately apparent but clearly paved the way to many of the recent developments in the field by providing the notion that $L p(a)$ is not a discrete lipoprotein species but rather a family of lipoprotein particles that has as a protein moiety a single copy of apo $\mathrm{B}$, more specifically apo $\mathrm{B}_{100}$ chemically linked to a single copy of apo(a) of a variable mass. However, species of $\mathrm{Lp}(\mathrm{a})$ that have $2 \mathrm{~mol}$ of apo(a) per mol of apo $B_{100}$ have been found $(17,18)$.

Early studies dealt with normotriglyceridemic subjects and the density limits used only permitted analyses of $L p(a)$ species having a core rich in cholesteryl esters (CEs). However, Bersot et al. (19), first noted that the apo(a) antigen can be present in chylomicrons and chylomicron remnants of subjects in the postprandial state. This finding prompted an inquiry into the relationship between triglyceride (TG)-rich particles and $\mathrm{Lp}(\mathrm{a})$ and between $\mathrm{Lp}(\mathrm{a})$ and hypertriglyceridemia in general. As an approach to this problem Scanu et al. (20) and Fless et al. (21) first established that the protein moiety of $\mathrm{Lp}(\mathrm{a})$, namely the apo B-apo(a) complex contrary to $\mathrm{apoB}_{100}$, is water soluble (Table I). This is likely because the highly glycosylated and hydrophilic apo(a) by linking to apo $B_{100}$ raises the overall hydrophilicity of the complex, thus preventing its precipitation. This observation may prove to be of a high biological significance since apo $\mathrm{B}_{100}$ once linked to apo(a) would be able to move in aqueous media independently from its association with lipids. Of additional importance is the fact that the apo B-apo(a) complex has lipophilic properties in that it can bind to artificial chylomicrons, TG-phospholipid emulsions, naturally occurring TG-rich particles (e.g., chylomicrons, chylomicron remnants, very low density lipoprotein [VLDL], and intermediate density lipoprotein [IDL]) as well as CE-rich lipoproteins (e.g., LDL and high density lipoprotein [HDL] although comparatively less effectively). Since apo(a) does not bind lipids, at least in its reduced and carboxymethylated form (21), it is apparent that the lipophilic properties of the apo B-apo(a) complex and its ability to affiliate with both CE- and TG-rich particles are due to apo $B_{100}$ which has been reported to undergo structural changes as a consequence of its chemical linkage to apo(a) (22).

From the above it is apparent that apo(a) not only serves as a distinctive marker of $\mathrm{Lp}(\mathrm{a})$ but also plays an important role in determining size and density of $\mathrm{Lp}(\mathrm{a})$ through its association with $\mathrm{apoB}_{100}$. With this notion in mind, let us now examine the unique structural properties of apo(a).

\section{Structure of apo(a)}

Joint studies between scientists at Genentech and the University of Chicago initiated in the late part of 1986 led to the discovery that a striking structural similarity exists between apo(a) and plasminogen based on partial amino acid sequence 
Table I. Water Solubility and Lipid-binding Capacity of Delipidated Human Plasma Lp(a)*

\begin{tabular}{lcc}
\hline \multicolumn{1}{c}{ Product } & Water soluble & Lipid binding \\
\hline Apo B100-apo(a) & Yes & Yes \\
Apo B100 & No* & Yes \\
Apo(a) & Yes & No \\
\hline
\end{tabular}

* Data taken from Fless et al. (21).

data (23) and the analysis of the apo(a) cDNA isolated from human liver libraries (24). The findings summarized in Table II showed that $(a)$ three of the five kringles (K) known to be present in plasminogen, e.g., $\mathrm{K}_{1}, \mathrm{~K}_{2}$, and $\mathrm{K}_{3}$, are missing in apo(a), (b), $\mathrm{K}_{4}$ however, is repeated many times, and (c) $\mathrm{K}_{5}$ is present as a single copy. It was also found that $\mathrm{K}_{4}$ apo(a) is highly homologous $(82-84 \%)$ to $\mathrm{K}_{4}$ of plasminogen, and that Ser is substituted for Arg at the site of activation to plasmin. Thus, apo(a) appears to be a giant zymogen that cannot be converted into an active fibrinolytic enzyme. The cDNA analyses have also shown that the 36 th $K_{4}$ of apo(a) has a cysteine residue, which likely is involved in the disulfide attachment of apo(a) to apo $B_{100}$, and that each kringle likely has aminolinked gycosylation sites contrary to the $K_{4}$ linking regions, 36 amino acids long, which has six $O$-linked glycosylation sites (25). The site of attachment of apo $B_{100}$ to apo(a) has not been clearly established although it appears to be in its carboxyl region as indicated by the observations that apo $B_{48}$ species are not found in $\mathrm{Lp}(\mathrm{a})$, and that apo $\mathrm{B}_{46}$ a mutant of apo $\mathrm{B}$ contains no apo(a) (Fless, G. M., S. Young, and A. M. Scanu, unpublished observations). The close structural relationship between apo(a) and plasminogen is also reflected by the immunological cross-reactivity between these two proteins (23), an observation that has stimulated recent developments of new specific techniques for their immunochemical quantification.

Thus the tools of molecular biology have further corroborated the notion of apo(a) heterogeneity and provided a framework for further structural and functional analyses of apo(a) isoforms. Apo(a) is considered to vary in size between 280 and $800 \mathrm{kD}$. These figures, however, may not be accurate because they are derived from electrophoretical analyses in low-percentage gel media generally not ideally suited for the molecular mass determination of glycoproteins also owing to the lack of suitable standards. It is also apparent that apo(a) with its predominant kringle structure and poor amphipilic properties cannot be considered as a true apolipoprotein. Because of its water solubility, it could occur in unconjugated form in the circulation; however, although very small amounts have been detected in the plasma, their artifactual derivation cannot be ruled out. Plasminogen also lacks the structural requirements for binding to lipids as well as the free cysteine residue present in apo(a). Thus, neither apo(a) nor plasminogen qualify as apolipoproteins. Unfortunately the terminology apo(a) has been in the literature for several years and it would be difficult to change it in spite of its inappropriateness. A schematic view of the structure of $\mathrm{Lp}(\mathrm{a})$ is presented in Fig. 1.

\section{Genetics of $\mathrm{Apo}(\mathrm{a})$}

In situ hybridization studies have localized the apo(a) gene to the long arm of chromosome 6 adjacent to the plasminogen gene $(26,27)$. A linkage between these two genes has been established from studies of a large kindred with a high incidence of premature cardiovascular disease $(28,29)$. According to Utermann et al. $(30,31)$, apo(a) is under the control of a single gene locus that specifies for several alleles each coding for an apo(a) isoform differing in size. In keeping with this concept are the observations from studies in humans (32) and in baboons (33) that show that there is a linear relation between the size of apo(a) RNA transcripts and apo(a) isoforms whose size is determined by the number of kringle 4 domains. Utermann and his colleagues (34) have identified by SDSPAGE isoforms designated $\mathrm{F}, \mathrm{B}$, or $\mathrm{S}$ with mobility that is either faster, equal to or slower than apo $B_{100}$, in keeping with the original observations by Fless et al. (16). Only one F and one $B$ isoform have been identified in contrast to four $S$ forms $\left(S_{1}, S_{2}, S_{3}\right.$, and $\left.S_{4}\right)$ that occur in a relatively high frequency. $A$ null allele was also postulated although only in operational terms since the complete absence of $L p(a)$ or apo(a) in plasma has not been established. Based on these observations and on the proposal that any individual exhibits either one or two isoforms, Utermann et al. (31) have suggested that the transmission of $L p(a)$ should obey a simple Mendelian mode with a

Table II. Structural Comparison between Human Plasma Apo(a) and Plasminogen

\begin{tabular}{|c|c|c|}
\hline Parameter & Apo(a) & Plasminogen \\
\hline Molecular weight & $280,000-800,000$ & $\approx 90,000$ \\
\hline Signal sequence & 19 residues* & 19 residues $^{\ddagger}$ \\
\hline $\mathrm{NH}_{2}$ terminus & Glu-GIn-Ser-His-Val-Val. . . & Glu-Pro-Leu-Asp-Asp-Tyr. . . \\
\hline Kringle 1 & Absent & 1 \\
\hline Kringle 2 & Absent & 1 \\
\hline Kringle 3 & Absent & 1 \\
\hline Kringle 4 & $13-37^{\S}$ & 1 \\
\hline Kringle 5 & 1 & 1 \\
\hline \multirow[t]{2}{*}{ Activation site } & Ser-Ile & Arg-Val \\
\hline & $4308-4309$ & $561-562$ \\
\hline Catalytic triad & Ser-His-Asp & Ser-His-Asp \\
\hline
\end{tabular}

\footnotetext{
*Apo(a): -Met-Glu-His-Lys-Glu-Val-Val-Leu-Leu-Leu-Leu-Leu-Phe-Leu-Lys-Ser-Ala-Ala-Pro ${ }^{\ddagger}$ Plasminogen: -Met-Glu-His-Lys-Glu-ValVal-Leu-Leu-Leu-Leu-Leu-Phe-Leu-Lys-Ser-Gly-Gln-Gly-. . . ${ }^{8}$ Isoforms with higher or lower $\mathrm{K}_{4}$ number are theoretically possible but not yet documented.
} 


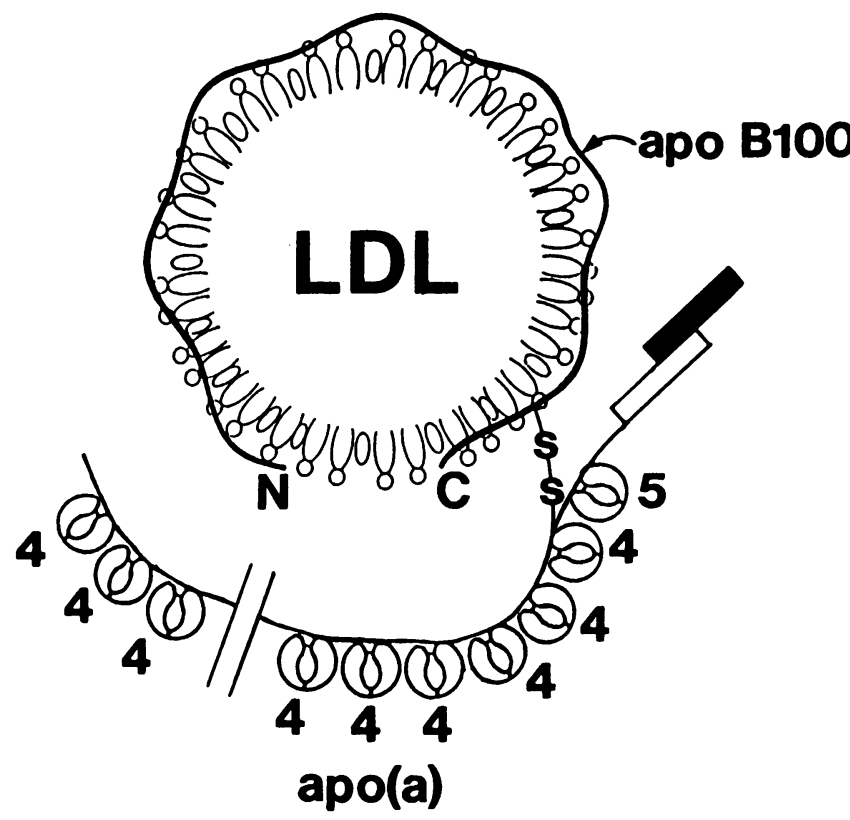

Figure 1. Schematic model of the structure of human plasma $L p(a)$. $\mathrm{Lp}(\mathrm{a})$ is made up of an LDL-like structure in which apo $B_{100}$, the protein moiety of authentic $\mathrm{LDL}$, is covalently linked to a glycoprotein, apo(a), which is the specific marker of $L p(a)$ and exhibits a striking similarity to plasminogen. The dominant structural motif of apo(a) is the "kringle," a three-disulfide, triple-loop structure named for its resemblance to a Danish pretzel. $K_{4}$ is repeated 13-37 times, whereas there is only one $k_{\mathbf{s}}$. It is now established that the size of each apo(a) isoform is under strict genetic control and determined by the number of kringles that it contains. Usually, there is $1 \mathrm{~mol}$ of apo(a) and $1 \mathrm{~mol}$ of apo $B_{100}$ in each $L p(a)$ particle. However, species of $L p(a)$ having one copy of apo $B_{100}$ and 2 mol of apo(a) have been reported (17).

codominant expression. This genetic model, however, must be considered tentative. At least 11 alleles and not just 6 have been observed by other investigators (35) and the contribution of polysaccharide chains to apo(a) polymorphism has not been critically taken into account. These uncertainties are compounded by the technical difficulty of unequivocally identifying plasma apo(a) phenotypes by SDS-PAGE particularly when dealing with individuals with low plasma levels of $\mathrm{Lp}(\mathrm{a})$. Thus, there is a need for improving the technology for apo(a) phenotyping, for establishing the actual number of the apo(a) isoforms, and for defining their physicochemical characteristics. Boerwinkle et al. (36) have also proposed that the apo(a) gene determines total plasma $L p(a)$ concentrations, and that there is an inverse relationship between apo(a) size and plasma Lp(a) levels. However, the apo(a) gene would only account for $\sim 40 \%$ of the Lp(a) levels, thus leaving unexplained the potential contribution of either genetic or environmental factors. Recently, Gavish et al. (37) by using probes specific for the $K_{4}$ and $\mathrm{K}_{5}$ domains of the apo(a) cDNA and quantitative Southern blotting analyses, have shown that the ratio of $K_{4} / K_{5}$ is inversely correlated with plasma $\mathrm{Lp}(\mathrm{a})$ concentrations. Moreover, an effect by the LDL receptor gene on plasma $\mathrm{Lp}(\mathrm{a})$ levels has recently been suggested from studies of $\mathrm{Lp}(\mathrm{a})^{+}$subjects with familial hypercholesterolemia (38). If this suggestion were to be true, factors affecting LDL receptor expression would be expected to have an effect on plasma $L p(a)$ levels. This, however, has not proven to be the case. For instance, 3-hydroxy-3-methylglutaryl coenzyme A (HMGCoA) reductase inhibitors have been shown either to have no significant effect $(39,40)$ or in one case, to raise plasma Lp(a) levels $(41)$. We have also recently shown that members of a rhesus monkey pedigree with a genetically based familial hypercholesterolemia exhibit no correlation between LDL receptor function and plasma $L p(a)$ levels $(42,43)$. Thus, there are uncertainties regarding the genetics of $L p(a)$ and the role that the apo(a) gene plays in determining apo(a) size polymorphism and plasma Lp(a) levels. These uncertainties are likely to persist until we gain knowledge on the structure of the apo(a) gene and on the factors affecting its expression.

\section{Regulatory events in Lp(a) synthesis and degradation}

Synthesis. The liver is the main and may be the sole site of production of $\mathrm{Lp}(\mathrm{a})$. Tomlinson et al. (44) found small amounts of apo(a) message in the testis and the brain of a male rhesus monkey but provided no documentation about apo(a) production by these organs. Current experimental evidence obtained from cultured hepatocytes, although not extensive, supports the view that the linkage between apo $B_{100}$ and apo(a) occurs intracellularly and that the apo $\mathrm{B}_{100^{-}} \mathrm{apo}(\mathrm{a})$ complex is incorporated into the $\mathrm{Lp}(\mathrm{a})$ complex before secretion. The best documentation comes from studies of cultured baboon primary hepatocytes (45) indicating that secreted products reacting with the anti-Lp(a) antibody floated in the density range of plasma $\mathrm{Lp}(\mathrm{a})$. However, this interpretation is not unequivocal since as we indicated earlier, the apo $B_{100}$-apo(a) complex is both hydrophilic and lipophilic and might acquire lipids after secretion from the liver cell. At this time we lack suitable cell culture models capable of expressing a sizable amount of apo(a) message either in the resting phase or after suitable upregulation. Considering the paucity of information it is not surprising that essentially nothing is known on the factors affecting the synthesis of the various $L p(a)$ components and their mode of assembly. The evidence that both (CE) Lp(a) and (TG)Lp(a) particles are present in the plasma invites one to consider that there are at least two distinct synthetic pathways which might be under different regulation.

Degradation. Whereas the site of synthesis of $\mathrm{Lp}(\mathrm{a})$ is reasonably well established, the issue concerning the mechanism(s) of degradation of this lipoprotein is still unsettled and characterized by a number of conflicting views. According to some studies, the LDL receptor is either not involved or only to a minimal extent (46-50) and probably does not contribute to Lp(a) catabolism in a major way. On the other hand, Floren et al. (48) and very recently, Hofmann et al. (51) have shown that intact $L p(a)$ binds with high affinity to the LDL receptor. Hofmann et al. (51) have also demonstrated that transgenic mice with an overexpression of the LDL receptor clear rapidly $\mathrm{Lp}$ (a) from the circulation. Evidence is now accruing in favor of a nonspecific receptor pathway, both in human skin fibroblast cultures $(46,52)$ and human monocyte-derived macrophages (Fless, G. M., M. Snyder, and A. M. Scanu, unpublished observations). However, the overall quantitative contribution by this pathway has not been established. The scavenger receptor does not appear to be significantly involved in $L p(a)$ degradation at least based on studies in human blood macrophages in culture and using native unmodified $L p(a)$ particles (53). Evidence in this direction comes also from studies in the rat (54). Yet Powell et al. (55) have recently reported that both human $\mathrm{Lp}(\mathrm{a})$ and recombinant apo(a) bind to the 
macrophage cell line P338D. It has also been shown that $\mathrm{Lp}(\mathrm{a})$ can bind to the plasminogen receptor $(56,57)$. This however, is not an endocytotic process and thus likely not involved in Lp(a) degradation to a significant extent. The recently published studies by Rath et al. (58) and Cushing et al. (59) showing that $L p(a)$ can accumulate in either the arterial wall and in vein grafts, respectively, suggest that this lipoprotein particle may be able to transverse the endothelium by non-receptormediated mechanisms (pinocytosis?). If this were to be the case, this transport process might be influenced by the density/size of $L p(a)$. In general, the interpretation of the binding and degradation studies has been complicated by the fact that Lp(a) preparations were pooled from several donors and that no attempt was made to distinguish between aggregated and monodisperse species. Moreover, in essentially all cases, the apo(a) phenotypes were not established.

Overall, we are still unclear about the factors that determine the plasma levels and distribution of the various $L p(a)$ particles. Turnover studies, thus far, have not been highly contributory in this regard although they have suggested a predominant role of synthesis over degradation $(50,52)$. Although the apo(a) gene may partially control the plasma Lp(a) levels, other factors are likely to be at play, involving other genes, hormones or environment.

\section{Physiological role and philogenetic considerations}

About $80 \%$ of the adult Caucasian white population regardless of age and gender has "normal levels" of plasma $\mathrm{Lp}(\mathrm{a})$ as reflected by the frequency distribution of plasma $\operatorname{Lp}(a)(30)$. Adult American blacks have levels of plasma $\mathrm{Lp}(\mathrm{a})$ that are higher than whites $(60)$ and this is also the case of black children (61). Considering the fact that everyone is $\mathrm{Lp}(\mathrm{a})^{+}$(a true null allele has not yet been unequivocally demonstrated), it is legitimate to ask what the physiological role of $\mathrm{Lp}(\mathrm{a})$ might be. In addition to humans, $L p(a)$ has been found in the plasma of nonhuman primates of the Old World (62) but not of the New World (63). No Lp(a) has been reported in the plasma of common laboratory animals (e.g., dogs, rats, mice etc.). On the other hand, relatively large amounts of $\mathrm{Lp}(\mathrm{a})$ have been reported in the plasma of the hedgehog, a hibernating animal low in the evolutionary scale (64). At this point, it is difficult to assess whether having $L p(a)$ in "normal ranges" is of any advantage. Considering that in man the levels of plasma LDL far exceed those of $\mathrm{Lp}(\mathrm{a})$, it is evident that only a relatively small percentage of the plasma pool of apo $\mathrm{B}_{100}$ and cholesterol (as well as phospholipids and TGs) are associated with Lp(a). However, this pool by escaping the LDL receptor degradation route may potentially become available for utilization at sites where there is rapid cell regeneration, active membrane biogenesis or an acute inflammatory process. $\mathrm{Lp}(\mathrm{a})$ has been reported to be an acute phase reactant $(65,66)$, although this observation has to be validated by more extensive studies. Overall, we know little about the physiological role of $\mathrm{Lp}(\mathrm{a})$. We also know little about the relation between plasma and tissue levels of $L p(a)$ and whether there is a physiological advantage to having one type of apo(a) isoform vs. another.

Lp(a) AS A CARDIOVASCULAR RISK

Several epidemiological studies have shown that high plasma levels of $\mathrm{Lp}(\mathrm{a})$ are associated with an increased risk for ASCVD (see for recent reviews references 30 and 67) and according to some it represents an independent risk factor for this disease $(7-9,11-13)$. However, the mechanism(s) for this pathogenicity is(are) unknown. From structural considerations it has been postulated that $\mathrm{Lp}(\mathrm{a})$ might have both proatherosclerotic and prothrombotic actions (68). We will briefly review this evidence and attempt to provide an integrated view of $\mathrm{Lp}(\mathrm{a})$ as a cardiovascular pathogen.

Proatherogenic role. Since $\mathrm{Lp}(\mathrm{a})$ particles appear to be a poor ligand for the LDL receptor, they may be assumed to be preferentially taken up by the scavenger receptor pathway and cause accumulation of cholesterol in macrophages and formation of foam cells which are precursors of the atherosclerotic process. However, cell culture studies thus far have not been supportive of this concept at least in the case of macrophages derived from human blood monocytes. Recent studies by Haberland et al. (53) have shown that contrary to the native products, $L p(a)$ particles where the lysine residues had been modified by malonyldialdehyde are readily taken up and degraded by macrophages. This conclusion is in keeping with the general concept that modified LDLs are atherogenic. Thus it is apparent that regardless of the mechanism, the plasma elevation of both $\mathrm{LDL}$ and $\mathrm{Lp}(\mathrm{a})$ would represent an additive risk as suggested by the recent studies by Armstrong et al. (11) and by Utermann et al. (38). Another possibility is that Lp(a) might transverse the endothelium by non-receptor-mediated mechanisms. The recent studies by Rath et al. (58) and Cushing et al. (59) may be interpreted to be in keeping with this concept based on the observations that $(a)$ in both studies, one dealing with arterial vessels (58) and the other with vein grafts (59), the tissue $\mathrm{Lp}(\mathrm{a})$ was remarkably undegraded and was predominantly extracellular, and $(b)$ in the Cushing studies the amount of $\mathrm{Lp}(\mathrm{a})$ that accumulated in the vein graft was proportional to the levels of plasma $L p(a)$. However, it is important to point out that the quantitive aspect of these studies is difficult to assess since little is known about the stability of tissue $\mathrm{Lp}(\mathrm{a})$ and the potential degradation attending tissue extraction procedures. Nonetheless, it is evident that a relatively large amount of $L p(a)$ can transverse the endothelium, possibly facilitated by a direct action of $\mathrm{Lp}(\mathrm{a})$ on endothelial functions. Once $L p(a)$ enters the arterial wall, it would interact with the tissue matrix (e.g., glycosaminoglycans, proteoglycans, etc.), undergo chemical modification, and become a candidate for uptake and degradation by macrophages through the scavenger receptor pathway in macrophages (69).

Prothrombotic role. The close structural similarity between apo(a) and plasminogen has invited studies assessing whether Lp(a) might have a prothrombotic role by interfering with the physiological functions of plasminogen. Investigations carried out in several laboratories have now shown that $L p(a)$ can compete in vitro with the binding of plasminogen to fibrinogen or fibrin monomer $(70,71)$ with the streptokinase-mediated activation of human plasminogen $(72,73)$ and the tissue plasminogen activator-mediated lysis of fibrin clots (70). It has been also shown that $L p(a)$ competes for the binding of plasminogen to the plasminogen receptor on endothelial cells and macrophages, at $\mathrm{Lp}(\mathrm{a})$ concentrations that are equivalent to those occurring in the circulation $(56,57,74)$. All of these actions by $L p(a)$, if they were to occur in vivo, could create a prothrombotic state. Moreover, owing to its preferential uptake and degradation by macrophages, $L p(a)$ could colocalize with fibrin at intimal tissue sites resulting in a complex which is also atherogenic.

OVERALL VIEW ON Lp(a) AS A CARDIOVASCULAR PATHOGEN From the data obtained thus far it is apparent that $L p(a)$ may 
have both athero- and thrombogenic roles, the former through its LDL-like characteristic and the latter through the plasminogen-like properties of apo(a). High levels of $\mathrm{Lp}(\mathrm{a})$ would be necessary for these actions but different species of $L p(a)$, e.g., (CE) $L p(a)$ vs. (TG) $L p(a)$, might also be important in this regard. Although $\mathrm{Lp}(\mathrm{a})$ has been suggested to act as an independent pathogen, other factors may contribute as well (e.g., dyslipoproteinemia, endothelial dysfunction, local inflammation, etc.). There is a need to further explore mechanisms on a cellular level and then obtain further clinical documentation of pathogenicity, keeping in mind that high plasma concentrations are needed for $\mathrm{Lp}(\mathrm{a})$ to have a pathogenic role.

\section{THERAPEUTIC CONSIDERATIONS}

The epidemiological evidence and the recent biochemical studies all pointing to an athero/thrombogenic role of $\mathrm{Lp}(\mathrm{a})$, have stimulated a great deal of interest in identifying means for bringing plasma Lp(a) down to "safe" levels. It is important to note, however, that it is not well established what these safe levels ought to be. Plasma $\mathrm{Lp}$ (a) can vary from barely detectable levels to $80 \mathrm{mg} / \mathrm{dl}$ (in terms of protein) or $340 \mathrm{mg} / \mathrm{dl}$ (in terms of total lipoprotein). Thus, although it is easy to recognize very low from very high values it is difficult to decide on intervention when confronted with middle range figures. At this time it might be reasonable to consider as normal plasma Lp(a) protein levels $<7 \mathrm{mg} / \mathrm{dl}[\sim 30 \mathrm{mg} /$ dl total $\mathrm{Lp}(\mathrm{a})]$. These are just orientation figures for directing therapy. At this time therapeutic considerations are based only on total plasma levels of $\mathrm{Lp}(\mathrm{a})$, but future programs may also have to address $\mathrm{Lp}$ (a) heterogeneity. In normotriglyceridemic states, dietary therapy has seen little success $(69,75)$. In fact, even in the experimental animal it has been impossible to influence plasma $L p(a)$ when using diets that caused a marked elevation of total LDL cholesterol (76). However, in $\mathrm{Lp}(\mathrm{a})^{+}$subjects with hypertriglyceridemia, some lowering of plasma Lp(a) may be achieved by the use of $\omega-3$ fatty acids which are able to decrease the hepatic synthesis and secretion of TG-rich particles or as recently reported by Gavish et al. (77) affect the postprandial association of apo(a) with TG-rich lipoprotein. In this case rather precise and sensitive techniques for measuring $\mathrm{Lp}(\mathrm{a})$ are needed, since the mass of $\mathrm{Lp}(\mathrm{a})$ associated with TGrich particles is rather small when compared to (CE) Lp(a) $(18,78)$.

In terms of drug therapy, the reported results do not encourage optimism. Drugs like bile acid sequestrants, niacin, or fibrates when used alone have been attended by mixed results (75). The same applies for HMGCoA reductase inhibitors (39, 40). In fact, in a recent study, lovastatin (41) has been reported to raise $L p(a)$ in $\sim 30 \%$ of the cases, suggesting that this HMGCoA reductase inhibitor might increase the hepatic synthesis of $L p(a)$. Niacin alone or in combination with either cholestyramine or neomycin has been reported to lower the plasma levels of $\mathrm{Lp}$ (a) (79-81). However, the beneficial effect was seen only in some cases with high plasma levels of $L p(a)$ and normalization of the values was not achieved. Moreover, no information was provided on whether the patients treated were normo- or hypertriglyceridemic. When the mechanism of action of the chosen drug is not understood and the presenting $\mathrm{Lp}$ (a) species are not defined, it is difficult to assess the true value of the reported observations. One must keep in mind that drugs used to lower plasma $L p(a)$ levels were designed for apoB and not apoB-apo(a) containing particles. Thus, it may be necessary to develop drugs specifically targeted to $\operatorname{Lp}(a)$. A possible approach would be to modify $\mathrm{Lp}(\mathrm{a})^{+}$into $\mathrm{Lp}(\mathrm{a})^{-}$particles by the removal of apo(a). This can be readily achieved in vitro by the use of a reducing agent $(30,67)$. Whether the same approach can also be safely used in vivo remains to be established. The most effective way to reduce the levels of plasma $\mathrm{Lp}(\mathrm{a})$ is $\mathrm{LDL}$ apheresis (82). However, this is an invasive approach that requires weekly treatments which at this time may not be considered a treatment of choice in subjects presenting with high plasma levels of $\mathrm{Lp}(\mathrm{a})$ but with no history of ASCVD.

\section{Concluding remarks}

The recent discovery that apo(a), the glycoprotein marker of Lp(a), has a striking structural similarity to plasminogen together with the clinical and experimental evidence that $\mathrm{Lp}(\mathrm{a})$ when present in high levels in the plasma may have atherogenic and thrombogenic potentials, have placed $\mathrm{Lp}(\mathrm{a})$ among the challenging areas of cardiovascular research. A lot has been learned in the past 4-5 years, but many unresolved questions still remain. We need to go into more depth regarding the regulatory mechanisms of synthesis, plasma transport and tissue degradation of $\mathrm{Lp}(\mathrm{a})$. We must gain a better perspective of the meaning of $L p(a)$ heterogeneity and also understand the actual role (either physiological or pathological) of the polymorphism of apo(a). The recent introduction of specific probes for apo(a) kringles (37) may aid in this direction. It would also be of importance to establish "normal" levels of $\mathrm{Lp}(\mathrm{a})$ and to elucidate the possible evolutionary advantage of having $L p(a)$ at all. In spite of the many uncertainties, it is apparent that the metabolic fate of $\operatorname{Lp}(\mathrm{a})$ is distinct from that of LDL. LDL has long been recognized as the major carrier of cholesterol in the plasma. $\operatorname{Lp}(a)$, on the other hand, might preferentially be involved in the regulation of the fibrinolytic system on the endothelial surface by acting as a competitor of plasminogen. The understanding of the pathophysiology of proteins that have a kringle domain has become a very active research area, particularly with regards to the factors that are involved in the coagulation and fibrinolytic systems. Just understanding how kringles work would be an achievement in itself.

\section{Acknowledgments}

The authors gratefully acknowledge the valuable help of Ms. Sue Hutchison in the preparation of the manuscript.

The original work by the authors cited in this review was supported by program project grant HL-18577 from the U. S. Public Health Service.

\section{References}

1. Berg, K. 1963. A new serum type system in man: the Lp system. Acta Pathol. Microbiol. Scand. 59:369-382.

2. Albers, J. J., J. L. Adolphson, and W. R. Hazzard. 1977. Radioimmunoassay of human plasma $\mathrm{Lp}(\mathrm{a})$ lipoprotein. J. Lipid Res. 18:331-338.

3. Walton, K. W., J. Hitchens, H. N. Magnani, and M. Khan. 1974. A study of methods of identification and estimation of $L p(a)$ lipoprotein and of its significance in health, hyperlipidaemia and atherosclerosis. Atherosclerosis. 20:323-346.

4. Dahlen, G., K. Berg, T. Gillnas, and C. Ericson. 1975. Lp(a) lipoprotein/pre-beta1-lipoprotein in Swedish middle-aged males and in patients with coronary heart disease. Clin. Genet. 7:334-341.

5. Frick, M. H., G. Dahlen, K. Berg, M. Valle, and P. Hekali. 1978. Serum lipids in angiographically assessed coronary atherosclerosis. Chest. 73:62-65. 
6. Berg, K. 1979. Inherited lipoprotein variation and atherosclerotic disease. In The Biochemistry of Atherosclerosis. A. M. Scanu, R. W. Wissler, and G. S. Getz, editors. Marcel Dekker, Inc., New York. 477-490.

7. Kostner, G. M., P. Avogaro, G. Cazzolato, E. Marth, G. BittoloBon, and G. B. Qunici. 1981. Lipoprotein Lp(a) and the risk for myocardial infarction. Atherosclerosis. 38:51-61.

8. Dahlen, G. H., M. Attar, and J. R. Guyton. 1983. Lipoprotein(a) and coronary artery disease. Arteriosclerosis. 3:478a. (Abstr.)

9. Koltringer, P. G., and G. Jurgens. 1985. A dominant role of lipoprotein(a) in the investigation and evaluation of parameters indicating the development of cervical atherosclerosis. Atherosclerosis. 58:187-198.

10. Murai, A., T. Miyahara, N. Fujimoto, M. Matsuda, and M. Kameyama. 1986. Lp(a) lipoprotein as a risk factor for coronary heart disease and cerebral infarction. Atherosclerosis. 59:199-204.

11. Armstrong, V. W., P. Cremer, E. Eberle, A. Manke, F. Schulze, H. Wieland, H. Kreuzer, and D. Seidel. 1986. The association between Lp(a) concentrations and angiographically assessed coronary atherosclerosis. Atherosclerosis. 62:249-257.

12. Dahlen, G. H., J. R. Guyton, M. Attar, J. A. Farmer, J. A. Kautz, and A. M. Gotto. 1986. Association of levels of lipoprotein Lp(a), plasma lipids, and other lipoproteins with coronary artery disease documented by angiography. Circulation. 74:758-765.

13. Rhoads, G. G., G. Dahlen G., K. Berg, N. E. Morton, and A. L. Dannenberg 1986. Lp(a) lipoprotein as a risk factor for myocardial infarction. JAMA (J. Am. Med. Assoc.). 256:2540-2544.

14. Durrington, P. N., M. Ishola, L. Hunt, S. Arrol, and D. Bhatnagar. 1988. Apolipoprotein(a), AI, and B and parental history in men with early onset ischaemical heart disease. Lancet. 1:1070-1073.

15. Harvie, N. R., and J. S. Schultz. 1973. Studies on the heterogeneity of human serum $\mathrm{Lp}$ lipoproteins and on the occurrence of double Lp lipoprotein variants. Biochem. Genet. 9:235-245.

16. Fless, G. M., C. A. Rolih, and A. M. Scanu. 1984. Heterogeneity of human plasma lipoprotein(a). J. Biol. Chem. 259:11470-11478.

17. Fless, G. M., M. E. ZumMallen, and A. M. Scanu. 1986. Physico-chemical properties of apolipoprotein(a) and lipoprotein (a-) derived from the dissociation of human plasma lipoprotein(a) J. Biol. Chem. 261:8712-8718.

18. Fless, G. M. 1990 . Heterogeneity of particles containing the apoB-apo(a) complex. In Lipoprotein(a): 25 Years of Progress. A. M. Scanu, editor. Academic Press, Inc., New York. In press.

19. Bersot, T. P., R. W. Innerarity, R. E. Pitas, S. C. Rall, L. J. Weisgraben, and R. W. Mahley. 1986. Fat feeding in humans induces lipoproteins of density less than 1.006 that are enriched in apolipoprotein(a) and that cause lipid accumulation in macrophages. J. Clin. Invest. 77:622-630.

20. Scanu, A. M., D. Pfaffinger, R. S. Rosenson, and G. M. Fless. 1987. Lipid-free apoB100-apolipoprotein(a) complex derived from lipoprotein(a) is water-soluble. Circulation. 76(Suppl. IV):116. (Abstr.)

21. Fless, G. M., D. J. Pfaffinger, J. D. Eisenbart, and A. M. Scanu, 1990. Solubility, immunochemical and lipoprotein binding properties of apoB ${ }_{100}$-apo(a), the protein moiety of lipoprotein(a) J. Lipid Res. In press.

22. Zawadzki, Z., F. Terce, L. J. Seman, R. T. Theolis, W. C. Breckenridge, R. W. Milne, and Y. L. Marcel. 1988. The linkage with apolipoprotein(a) in lipoprotein(a) modifies the immunochemical and functional properties of apolipoprotein B. Biochemistry. 27:84748481.

23. Eaton, D. L., G. M. Fless, W. J. Kohr, J. W. McLean, Q. Xu, C. G. Miller, R. M. Lawn, and A. M. Scanu. 1987. Partial amino acid sequence of apolipoprotein(a) shows that it is homologous to plasminogen. Proc. Natl. Acad. Sci. USA. 84:3224-3228.

24. McLean, J. W., J. E. Tomlinson, W. Kuang, D. L. Eaton, E. Y. Chen, G. M. Fless, A. M. Scanu, and R. M. Lawn. 1987. cDNA sequence of human apolipoprotein(a) is homologous to plasminogen. Nature (Lond.). 330:132-137.

25. Kratzin, H., V. W. Armstrong, M. Niehaus, N. Hilschmann, and D. Seidel 1987. Structural relationship of an apolipoprotein(a) phenotype $(570 \mathrm{k} \mathrm{Da})$ to plasminogen: homologous kringle domains are linked by carbohydrate-rich regions. Biol. Chem. Hoppe-Seyler. 368:1533-1544.

26. Frank, S. L., I. Klisak, R. S. Sparkes, T. Mohandas, J. E. Tomlinson, J. W. McLean, R. M. Lawn, and A. J. Lusis. 1988. The apolipoprotein(a) gene resides on human chromosome $6 \mathrm{q} 26-27$, in close proximity to the homologous gene for plasminogen. Hum. Genet. 79:352-356.

27. Lindhal, G., E. Gersdorf, H. J. Menzel, C. Duba, H. Cleve, S. Humphries, and G. Utermann. 1989. The gene for the Lp(a)-specific glycoprotein is closely linked to the gene for plasminogen on chromosome 6. Hum. Genet. 81:149-152.

28. Drayna, D. T., R. A. Hegele, P. E. Hass, M. Emi, L. L. Wu, D. L. Eaton, R. M. Lawn, R. R. Williams, R. L. White, and J. M. Lalouel. 1988. Genetic linkage between lipoprotein(a) phenotype and a DNA polymorphism in the plasminogen gene. Genomics. 3:230236.

29. Hegele, R. A., L. L. Wu, and R. R. Williams. 1990. Lipoprotein(a) and plasminogen: linkage analysis. In Lipoprotein(a): 25 Years of Progress. A. M. Scanu, editor. Academic Press, Inc., New York. In press.

30. Utermann, G. 1989. The mysteries of lipoprotein(a). Science (Wash. DC). 246:904-910.

31. Utermann, G. H., J. Menzel, H. G. Kraft, H. C. Duba, H. G. Kemmler, and C. Selz. 1987. Lp(a) glycoprotein phenotypes: inheritance and relation to $\mathrm{Lp}(\mathrm{a})$-lipoprotein concentrations in plasma. $J$. Clin. Invest. 80:458-465.

32. Koschinski, M., U. Beisiegel, J. Tomlinson, and R. Lawn. 1989. Apolipoprotein(a) size heterogeneity is related to variable repeat sequences in its mRNA. Circulation. 80:II-464. (Abstr.)

33. Hixson, J. E., S. Britten, G. Manis, and D. L. Rainwater. 1989. Apolipoprotein(a)apo(a) glycoprotein isoforms result from size differences in apo(a) mRNA in baboons. J. Biol. Chem. 264:6013-6016.

34. Utermann, G. 1990. Genetics of the Lp(a) lipoprotein. In Lipoprotein(a): 25 Years of Progress: A. M. Scanu, editor. Academic Press, Inc., New York. In press.

35. Morrisett, J. D., J. W. Gaubatz, R. D. Knapp, and J. G. Guevara, Jr. 1990. Structural properties of apo(a) a major apoprotein of human lipoprotein(a). In Lipoprotein(a): 25 Years of Progress. A. M. Scanu, editor. Academic Press, Inc., New York. In press.

36. Boerwinkle, E., H. J. Menzel, H. G. Kraft, and G. Utermann. 1989. Genetics of the quantitative Lp(a) lipoprotein trait. III. Contribution of $\mathbf{L p}(a)$ glycoprotein phenotypes to normal lipid variation. Hum. Genet. 82:73-78.

37. Gavish, D., N. Azrolan, and J. Breslow. 1989. Plasma Lp(a) concentration is inversely correlated with the ratio of kringle IV/kringle $\mathrm{V}$ encoding domains in the apo(a) gene. J. Clin. Invest. 84:20212027.

38. Utermann, G., F. Hoppichler, and H. Dieplinger. 1989. Defects in the low density lipoprotein receptor gene affect lipoprotein(a) levels: multiplicative interaction of two gene loci associated with premature atherosclerosis. Proc. Natl. Acad. Sci. USA. 86:4171-4174.

39. Thiery, J., V. W. Armstrong, J. Schleef, C. Creutzfeldt, W. Creutzfeldt, and D. Seidel. 1988. Serum lipoprotein Lp(a) concentrations are not influenced by HMGCoA reductase inhibitor. Klin. Wochenshr. 66:462-463.

40. Leren, T. P., I. Hjermann, K. Berg, P. Leren, O. P. Foss, and L. Viksmoen. 1988. Effects of lovastatin alone and in combination with cholestyramine on serum lipids and apolipoproteins in heterozygotes for familial hypercholesterolemia. Atherosclerosis. 73:135-141.

41. Kostner, G. M., D. Gavish, B. Leopold, K. Bolzano, M. S. Weintraub, and J. L. Breslow. 1989. HMGCoA reductase inhibitors lower LDL cholesterol without reducing Lp(a) levels. Circulation. 80:1313-1319.

42. Scanu, A. M., D. Pfaffinger, and G. M. Fless. 1989. Relation of apo(a) size polymorphism to plasma Lp(a) level and LDL-receptor activity in a rhesus monkey pedigree. Arteriosclerosis. 9:700a. (Abstr.)

43. Neven, L., A. Khalil, D. Pfaffinger, G. M. Fless, E. Jackson, and A. M. Scanu. 1990. Rhesus monkey model of familial hypercholester- 
olemia: relation between plasma $\operatorname{Lp}(a)$ levels, apo(a) isoforms and LDL-receptor function. J. Lipid. Res. In press.

44. Tomlinson, J. E., J. W. McLean, and R. M. Lawn. 1989. Rhesus monkey apolipoprotein(a): sequence, evolution and site of synthesis. J. Biol. Chem. 264:5957-5965.

45. Rainwater, D. L., and R. E. Lanford. 1989. Production of lipoprotein(a) by primary baboon hepatocytes. Biochim. Biophys. Acta. 1003:30-35.

46. Maartmann-Moe, K., and K. Berg. 1981. Lp(a) lipoprotein enters cultured fibroblasts independently of the plasma membrane low density lipoprotein receptor. Clin. Genet. 20:352-362.

47. Havekes, L., B. J. Vermeer, T. Brugman, and J. Emeis. 1981. Binding of $\mathrm{Lp}(\mathrm{a})$ to the low density lipoprotein receptor of human fibroblasts. FEBS (Fed. Eur. Biochem. Soc.) Lett. 132:169-173.

48. Floren, C. H., J. J. Albers, and E. L. Bierman. 1981. Uptake of Lp(a) lipoprotein by cultured fibroblasts. Biochem. Biophys. Res. Commun. 102:636-639.

49. Armstrong, V. W., A. K. Walli, and D. Seidel. 1985. Isolation, characterization, and uptake in human fibroblasts of an apo(a)-free lipoprotein obtained on reduction of lipoprotein(a). J. Lipid Res. 26:1314-1323.

50. Krempler, F., G. M. Kostner, A. Roscher, F. Haslauer, K. Bolzano, and F. Sandhofer, 1983. Studies on the role of specific cell surface receptors in the removal of lipoprotein(a) in man. J. Clin. Invest. 71:1431-1441.

51. Hofmann, S. L., D. L. Eaton, M. S. Brown, W. J. McConathy, J. L. Goldstein, and R. E. Hammer. 1990. Overexpression of human LDL receptors leads to accelerated catabolism of $\mathrm{Lp}(\mathrm{a})$ lipoprotein in transgenic mice. J. Clin. Invest. In press.

52. Mann, A. W., H. G. Kraft, J. J. Rader, J. R. Schaefer, L. A. Zach, R. E. Gregg, J. M. Hoeg, and H. B. Brewer, Jr. 1989. Human in vivo catabolism of lipoprotein(a). Circulation. 80:II-181.

53. Haberland, M. E., G. Fless, A. M. Scanu, and A. M. Fogelman. 1989. Modification of Lp(a) by malondialdehyde leads to avid uptake by human monocyte-macrophages. Circulation. 80:II-163.

54. Harkes, L., G. Jurgens, A., Holasek and T. J. C. Berkel. 1988. In vivo studies on the binding sites for lipoprotein(a) on parenchymal and non-parenchymal rat liver cells. FEBS (Fed. Eur. Biochem. Soc.) Lett. 229:27-31.

55. Powell, L. M., G. Rice, R. Lawn, and D. Eaton. 1989. Binding of $\mathrm{Lp}(\mathrm{a})$ and recombinant apo(a) to the mouse macrophage cell line P388D. Circulation. 80II, 181.

56. Miles, L. A., G. M. Fless, E. G. Levin, A. M. Scanu, and E. F. Plow. 1989. A potential basis for the thrombotic risks associated with lipoprotein(a). Nature (Lond.). 339:301-303.

57. Hajjar, K. A., D. Gavish, J. L. Breslow, and R. L. Nachman. 1989. Lipoprotein(a) modulation of endothelial cell surface fibrinolysis and its potential role in atherosclerosis. Nature (Lond.). 339:303305.

58. Rath, M., A. Niendorf, T. Reblin, M. Dietel, H. J. Krebber, and U. Beisiegel. 1989. Detection and quantitation of Lipoprotein(a) in the arterial wall of 107 coronary bypass patients. Arteriosclerosis. 9:579592.

59. Cushing, G. L., J. W. Gaubatz, M. L. Nava, B. J. Burdick, T. M. A. Bocan, J. R. Guyton, D. Weilbaecher, M. E. DeBakey, G. M. Lawrie, and J. D. Morrisett. 1989. Quantitation and localization of apolipoprotein(a) and B in coronary artery bypass vein grafts resected at re-operation. Arteriosclerosis. 9:593-603.

60. Guyton, J. R., G. H. Dahlen, W. Patsch, J. A. Kautz, and A. M. Gotto, Jr. 1985. Relationship of plasma lipoprotein Lp(a) levels to race and to apolipoprotein B. Arteriosclerosis. 5:265-272.

61. Levitsky, L. L., A. M. Scanu, and S. H. Gould. 1990. Lipoprotein(a) levels are related to glycemic control in white diabetic children. Pediatr. Res. In press.

62. Scanu, A. M. 1990. Lp(a) in non-human primates: relation to man. In From Phenotype to Gene in Common Disorders. K. Berg, editor. Munksgaard A/S International Publishers, Copenhagen. In press.
63. Makino, K., A. Abe, S. Maeda, A. Noma, M. Kawade, and O. Takenaka. 1989. Lipoprotein(a) in nonhuman primates. Presence and characteristics of $\mathbf{L p}(a)$ immunoreactive materials using antihuman Lp(a) serum. Atherosclerosis. 78:81-85.

64. Laplaud, P. M., L. Beaubatie, S. J. Rall Jr, G. Luc, and M. Saboureau. 1988. Lipoprotein(a) is the major apoB-containing lipoprotein in the plasma of a hibernator, the hedgehog. J. Lipid. Res. 29:1157-1170.

65. Dahlen, G. H. Incidence of $L p(a)$ among populations. In Lipoprotein(a): 25 Years of Progress. A. M. Scanu, editor. Academic Press, Inc., New York. In press.

66. Maeda, S., A. Abe, M. Seishima, K. Makino, A. Norma, and M. Kawade. 1989. Transient changes of serum lipoprotein(a) as an acute phase protein. Atherosclerosis. 78:145-150.

67. Scanu, A. M., and L. Scandiani. 1990. Lipoprotein(a): structure, biology and clinical relevance. Adv. Intern. Med. In press.

68. Scanu, A. M. 1988. Lp(a) A potential bridge between the fields of atherosclerosis and thrombosis. Arch. Pathol. Lab. Med. 112:10451047.

69. Kostner, G. M. 1990. Is there a physiological role of $L p(a)$. In Lipoprotein(a): 25 Years of Progress. A. M. Scanu, editor. Academic Press, Inc., New York. In press.

70. Loscalzo, J., M. Weinfeld, G. M. Fless, and A. M. Scanu. 1990. Lipoprotein(a), fibrin binding and plasminogen activation. Arteriosclerosis. 10:240-245.

71. Harpel, P. C., B. R. Gordon, and T. S. Parker. 1989. Plasmin catalyzes binding of lipoprotein(a) to immobilized fibrinogen and fibrin. Proc. Natl. Acad. Sci. USA. 86:3847-3851.

72. Edelberg, J. M., M. Gonzalez-Gronow, and S. V. Pizzo. 1989. Lipoprotein(a) inhibits streptokinase-mediated activation of human plalminogen. Biochemistry. 28:2370-2374.

73. Karadi, I., G. M. Kostner, A. Gries, J. Nimpf, L. Romics, and E. Malle. 1988. Lipoprotein(a) and plasminogen are immunochemically related. Biochim. Biophys. Acta. 960:91-97.

74. Gonzalez-Gronow, M., J. M. Edelberg, and S. V. Pizzo. 1989. Further characterization of the cellular plasminogen binding site: evidence that plasminogen 2 and lipoprotein a compete for the same site. Biochemistry. 28:2374-2377.

75. Brewer, H. B. 1990. Effectiveness of diet and drugs in the treatment of patients with elevated Lp(a) levels. In Lipoprotein(a): 25 Years of Progress. A. M. Scanu, editor. Academic Press, Inc., New York. In press.

76. Fless, G. M., K. Fisher-Dzoga, D. J. Juhn, S. Bates, and A. M. Scanu. 1982. Structural and functional changes of rhesus serum low density lipoproteins during cycles of diet-induced hypercholesterolemia. Arteriosclerosis. 2:475-486.

77. Gavish, D., Azolan, N., and J. L. Breslow. 1990. Fish oil reduces plasma $\operatorname{Lp}(a)$ levels and affects postprandial association of apo(a) with triglyceride-rich lipoproteins. Clin. Res. In press.

78. Fless, G. M., M. L. Snyder, and A. M. Scanu. 1989. Enzyme linked immunoassay for Lp(a). J. Lipid Res. 30:651-662.

79. Carlson, L. A., A. Hamsten, and A. Asplund. 1989. Pronounced lowering of serum levels of lipoprotein Lp(a) in hyperlipidaemic subjects treated with nicotinic acid. J. Intern. Med. 226:271-276.

80. Lin, J. T., G. Brown, J. L. Adolphson, and J. J. Albers. 1988. Lipoprotein(a) predicts coronary disease severity among hyperlipidemic men, and responds to lipid-lowering therapy. Arteriosclerosis. 8:576a. (Abstr.)

81. Gurakar, A., J. M. Hoeg, G. Kostner, N. M. Papdopoulos, and H. B. Brewer Jr. 1985. Levels of lipoprotein Lp(a) decline with neomycin and niacin treatment. Atherosclerosis. 57:293-301.

82. Armstrong, V. W., J. Schleef, J. Thiery, R. Muche, P. SchuffWerner, T. Eisenhauer, and D. Seidel. 1989. Effect of HELP-LDLapheresis on serum concentrations of human lipoprotein(a): kinetic analysis of the posttreatment return to baseline levels. Eur. J. Clin. Invest. 19:235-240. 